\title{
Physical activity and depressive symptoms after stillbirth: informing future interventions
}

\author{
Jennifer Huberty ${ }^{1 *}$, Jenn A Leiferman ${ }^{2}$, Katherine J Gold ${ }^{3,4}$, Lacey Rowedder ${ }^{1}$, Joanne Cacciatore ${ }^{5}$ \\ and Darya Bonds McClain ${ }^{6}$
}

\begin{abstract}
Background: In the United States, approximately one in 110 pregnancies end in stillbirth affecting more than 26,000 women annually. Women experiencing stillbirth have a threefold greater risk of developing depressive symptoms compared to women experiencing live birth. Depression contributes negatively to health outcomes for both mothers and babies subsequent to stillbirth. Physical activity may improve depression in these women, however, little is known about acceptable physical activity interventions for women after stillbirth. This is the purpose of this descriptive exploratory study.
\end{abstract}

Methods: Eligible women were between ages 19 and 45, and experienced stillbirth within one year of the study. An online survey was used to ask questions related to 1) pregnancy and family information (i.e., time since stillbirth, weight gain during pregnancy, number of other children) 2) physical activity participation, 3) depressive symptomatology, and 4) demographics.

Results: One hundred seventy-five women participated in the study ( $M$ age $=31.26 \pm 5.52$ ). Women reported participating in regular physical activity (at least 150 minutes of moderate activity weekly) before (60\%) and during (47\%) their pregnancy, as well as after their stillbirth (61\%). Only 37\% were currently meeting physical activity recommendations. Approximately $88 \%$ reported depression (i.e., score of $>10$ on depression scale). When asked how women cope with depression, anxiety, or grief, 38\% said physical activity. Of those that reported using physical activity to cope after stillbirth, they did so to help with depression (58\%), weight loss (55\%), and better overall physical health (52\%). To cope with stillbirth, women used walking (67\%), followed by jogging (35\%), and yoga (23\%). Women who participated in physical activity after stillbirth reported significantly lower depressive symptoms $(M=15.10, S D=5.32)$ compared to women who did not participate in physical activity $(M=18.06$, $S D=5.57 ; t=-3.45, p=.001)$.

Conclusions: Physical activity may serve as a unique opportunity to help women cope with the multiple mental sequelae after stillbirth. This study provides data to inform healthcare providers about the potential role of physical activity in bereavement and recovery for women who have experienced stillbirth. Additional research is necessary in this vulnerable population.

Keywords: Stillbirth, Perinatal loss, Exercise, Yoga, Mental health

\section{Background}

Approximately one in 110 pregnancies end in stillbirth (intrauterine death of a baby at or after the $20^{\text {th }}$ completed gestational week), affecting more than 26,000 women annually $[1,2]$ in the United States. After giving birth (both live and stillbirth), women may experience

\footnotetext{
* Correspondence: Jhuberty@asu.edu

${ }^{1}$ Exercise and Wellness, Arizona State University, Phoenix, AZ, USA

Full list of author information is available at the end of the article
}

significant physical, mental, and social maladies including alterations in appetite and sleep patterns, guilt and shame, and depression [3-5]. However, women who experience stillbirth are at three times the risk of developing depressive symptoms compared to women who had a live birth [5-7]. In a recent study, 7-8\% of women with a live birth experienced symptoms of posttraumatic stress compared to $44 \%$ of women who experienced stillbirth [8]. Depressive states may contribute to excessive 
weight retention/gain, chronic disease risk (i.e., heart disease, diabetes), premature mortality, and can negatively impact the health of babies born subsequent to stillbirth [9]; the majority of which (50-98\%) are conceived within a year after stillbirth [10-12]. Women who have experienced stillbirth are medically high-risk and vulnerable, underscoring the need to identify efforts to enhance their mental and physical health.

Inter-conception care is provided to women of reproductive age between pregnancies. The goal of interconception care is the same as pre-conception care, to ensure that conditions and behaviors, which may pose maternal and infant risks, are identified and managed [13]. Unfortunately, inter-conception interventions to improve the mental and physical health of women who have experienced a stillbirth are essentially non-existent. Most often treatment for bereaved mothers is mirrored after women who have experienced a live birth (i.e., return for a 6-week check-up) and may include psychiatric medications [14], and/or, when available, referral to social support groups [15]. Thus, the development of inter-conception interventions specifically designed to decrease negative psychiatric sequalae and increase positive coping after stillbirth is critical to individual, familial, and public health.

Physical activity improves depressive symptoms in a number of populations and has been shown to be more efficacious than psychiatric medications [16-18]. Additionally, women who are active during and after pregnancy have fewer depressive symptoms and report better mood as compared to inactive pregnant and post-partum women [19-21]. It is unknown whether this also applies to women who have experienced stillbirth. In a study by Huberty et al. [22], women who have experienced a stillbirth who reported regular physical activity described mental, emotional, and physical benefits that helped them better cope with grief [22]. The same mothers also felt that activity helped them better cope with emotional stressors related to stillbirth [23]. Even mothers who were not regularly active reported that when they were active they felt better, had a better mindset, and had more energy [22]. The literature suggests a number of mechanisms for the physical activity-depression relationship including elevated body temperature, increases in endorphins and neurotransmitters, and improvements in self-efficacy [23]. Some of these same mechanisms may occur in women who have experienced stillbirth.

Unfortunately, little is known about what type of physical activity interventions are acceptable for women who experienced stillbirth. Women with a live birth report lack of time, motivation, child-care, and other adjustments to parenting (i.e., more responsibility, prioritizing) as major barriers to physical activity participation [24-27]. However, women who experienced stillbirth report barriers to physical activity participation unique to stillbirth [22] such as emotional symptoms (i.e., feeling depressed, emotionally drained) and diminished motivation, being tired, feeling guilt, having a pregnant body with no baby, and being confronted with other babies (i.e., exercise in public settings, outside the home) [22]. Understanding the specific physical activity preferences for these women could inform targeted physical activity interventions.

Therefore, the purpose of this study was to learn more about women's desire to use physical activity to improve depressive symptoms after stillbirth, and their experience with physical activity after stillbirth. Findings from this study will be used to inform the design of inter-conception interventions to improve mental and physical health in these women.

\section{Methods}

This was a descriptive exploratory study that used a convenient non-probabilistic sample. The Institutional Review Board at Arizona State University approved the study.

\section{Participants}

Women were eligible to participate in the study if they were 19 to 45 years of age, lived in the United States, spoke English, and experienced the death of a baby to stillbirth within one year of participation. Current pregnancy was not an exclusion from the study. Women were recruited locally and nationally through collaboration with non-profit stillbirth advocacy organizations (e.g., Star Legacy Foundation, Still Standing Magazine), posting flyers at venues (e.g., hospitals, physician clinics) and snowball sampling (i.e., sharing information about the studies with others) through social media (e.g., Facebook, Twitter).

\section{Procedures}

Recruitment for the study occurred between February 2014 and July of 2014. The survey was free, voluntary, and available online. Women who chose to complete the survey either entered a link online from the recruitment materials (i.e., fliers) or clicked on an internet link (e.g., Facebook, email). The survey was hosted by Qualtrics (Provo, Utah). Completion of the survey was taken as consent. Participants were allowed to choose no response or skip questions in the survey. At the end of the survey, participants had the opportunity to provide their email address if they wished to be contacted for future studies.

\section{Survey}

The survey included the following four sections: (1) Pregnancy and family information ( $\mathrm{n}=5$ items). Questions in this section were related to time since stillbirth, weight 
gain during pregnancy, and number of other children. (2) Physical activity participation over time (i.e., before pregnancy, during pregnancy, after stillbirth; $\mathrm{n}=6$ items). An example question includes, "In the time since your loss, have you participated in exercise or physical activity?" (3) Physical Activity and Depressive Symptomatology $(\mathrm{n}=20$ items). Questions were related to a history of diagnosis of depressive mood disorder and coping with depressive symptoms (i.e., preferences for physical activity). (4) Demographics (i.e., race, ethnicity, income, education; $\mathrm{n}=8$ items).

To define and assess physical activity before, during, and after their most recent pregnancy as well as currently, a modified version of the Physical Activity Stages of Change Questionnaire was used [28]. The Edinburgh Postnatal Depression Scale (EPDS) was used to determine depressive symptomatology and is a reliable and valid tool for use in women who experienced stillbirth [29]. Scores above 13 on the EPDS indicated high depressive symptomatology [30].

\section{Data analysis}

Descriptive statistics (e.g., means, percentages) for all the survey questions were calculated. The number of women currently meeting physical activity recommendations of 150 minutes of moderate intensity physical activity [31] each week was determined by multiplying the amount of days they reported being active by the time per day spent practicing physical activity. Options for the "time per day" question were expressed in a range (i.e. 15-29 minutes), and the lowest number in the range was used for the calculation. An independent t-test was used to compare average level of self-reported depressive symptoms in women who participated in physical activity and was compared to those that did not participate in physical activity since experiencing stillbirth. A linear regression model estimated the relationship between physical activity after stillbirth while controlling for time since stillbirth and history of depressive disorder diagnosis. A chi-square test was conducted to compare the proportion of women who scored above the depression threshold on the EPDS across physical activity groups (active (meeting recommendations of 150 minutes per week) [31] as compared to inactive (i.e., not meeting recommendations) since stillbirth).

\section{Results}

\section{Participant characteristics}

Three hundred fifty two women clicked on the link to participate in the survey. Of these 297 completed the survey (84\%), 38 were excluded for residency outside of the U.S., six were excluded for being over the age of 45 years, 49 were excluded for being more than one year since stillbirth, and 29 had missing data related to the date of their stillbirth. A total of 175 (50\%) of women who had experienced stillbirth in the past year were included in the final analysis and were between the ages of 19-45 years (mean $31.26 \pm 5.52$ years). A majority of the women were married (83\%), Caucasian $(86.5 \%)$ and were living in the southern portion of the United States (43\%). One-third of our sample reported prior diagnosis with a depressive mood disorder and of those $59 \%$ had been diagnosed within the past year. Almost $40 \%$ of our sample had experienced their stillbirth within the last three months. All demographics are presented in Table 1.

\section{Physical activity participation and depressive symptoms}

Information about using physical activity to cope with depressive symptoms is presented in Table 2. Approximately $60 \%$ of the sample reported participating in regular physical activity (meeting recommendations of 150 minutes per week) [31] before their pregnancy and $47 \%$ participated during their pregnancy. Of the women reporting participation in physical activity since their stillbirth ( $\mathrm{n}=104,61 \%)$, only 38 women (37\%) met current physical activity recommendations of at least 150 minutes weekly. Most women reported engaging with friends/family (72\%), participating in group support (52\%), and physical activity (38\%) as a means to cope with their depressive symptoms. Of those that reported engaging in physical activity, the most important reasons were to help with depressive symptoms (58\%), lose weight (55\%), and to have better overall physical health (i.e., fitness) (52\%). When asked what type of physical activity women used to cope with their depressive symptoms, most said walking (67\%), followed by jogging (35\%), and yoga (23\%). Although less than $20 \%$ of women reported trying yoga as a means to cope with depressive symptoms, almost $50 \%$ were interested in using yoga to cope and of these, $80 \%$ would prefer to do yoga in their home.

\section{Relationship between physical activity participation and depression scores}

Women who reported participating in regular physical activity since their stillbirth reported significantly lower levels of depressive symptoms (Mean $(M)=15.10, S D=5.32$ ) compared to women who did not participate in regular physical activity $(M=18.06, S D=5.57 ; t=-3.45, p=.001)$. Linear regression model results $\left(\mathrm{F}=10.79, \mathrm{p}=.00 ; R^{2}=.17\right)$ indicated that the relationship between physical activity and depressive symptoms remained significant $(\beta=-.26$, $p=.00)$ after controlling for time since stillbirth $(\beta=-.12$, $p=.09$ ) and history of depressive disorder diagnosis $(\beta=.30, p=.00)$. There was also a significant difference when comparing the proportion of women scoring above the depression threshold who participated physical activity since the stillbirth (57\%) versus those who did not participate in physical activity $\left(78 \% ; X^{2}=7.43, p=.01\right)$. 
Table 1 Demographics of participants $(\mathbf{N}=175)$

\begin{tabular}{|c|c|}
\hline & $\mathrm{n} \%$ \\
\hline \multicolumn{2}{|l|}{ Zip code $(n=120)$} \\
\hline West & $27(22.5)$ \\
\hline Midwest & $30(25.0)$ \\
\hline Northeast & $11(9.2)$ \\
\hline South & $52(43.3)$ \\
\hline \multicolumn{2}{|l|}{ Race $(n=155)$} \\
\hline Caucasian & $134(86.5)$ \\
\hline African American & $5(3.2)$ \\
\hline Asian & $1(0.6)$ \\
\hline American Indian & $3(2.0)$ \\
\hline Other & $12(7.7)$ \\
\hline \multicolumn{2}{|l|}{ Education level $(n=155)$} \\
\hline$<$ High School & $3(2.0)$ \\
\hline High School Diploma & $23(14.8)$ \\
\hline Some College & 35 (22.6) \\
\hline Associates Degree & $25(16.1)$ \\
\hline Bachelors Degree & $33(21.3)$ \\
\hline Graduate School+ & $36(23.2)$ \\
\hline \multicolumn{2}{|l|}{ Income $(n=154)$} \\
\hline$<\$ 20,000$ & $26(16.9)$ \\
\hline$\$ 21,000-\$ 40,000$ & 44 (28.6) \\
\hline$\$ 41,000-\$ 60,000$ & $23(14.9)$ \\
\hline$\$ 61,000+$ & $61(39.6)$ \\
\hline \multicolumn{2}{|l|}{ Marital Status $(n=155)$} \\
\hline Single & $6(3.9)$ \\
\hline Partnered/In a relationship & $20(12.9)$ \\
\hline Married & $128(82.6)$ \\
\hline Divorced & $1(0.6)$ \\
\hline Age $(n=169)$ & mean $=31.62 \pm 5.52$ \\
\hline $18-24$ & $26(15.4)$ \\
\hline $25-29$ & $40(23.7)$ \\
\hline $30-34$ & $58(34.3)$ \\
\hline $35-39$ & $34(20.1)$ \\
\hline $40-45$ & $11(6.5)$ \\
\hline \multicolumn{2}{|l|}{ Time since loss $(n=175)$} \\
\hline $0-3$ months & $68(38.9)$ \\
\hline 4-6 months & $34(19.4)$ \\
\hline 7-9 months & $41(23.4)$ \\
\hline 10-12 months & $32(18.3)$ \\
\hline
\end{tabular}

\section{Discussion}

This was the first study to determine women's preferences for and experiences with physical activity after stillbirth. As such, it offers information necessary for healthcare providers to design and implement inter- conception interventions that include physical activity to improve the mental and physical health of women after stillbirth, an area which is lacking. Women who have experienced stillbirth are a high-risk population for poor maternal and infant health outcomes because of the negative health implications (i.e., depressive symptoms, weight retention) due to the traumatic event (i.e., stillbirth) and the high rate of conceiving within a year after the stillbirth. The encouragement of positive health behaviors such as physical activity in women who have experienced stillbirth during inter-conception care may positively impact maternal and fetal health outcomes in subsequent pregnancies. Unfortunately, health care providers are not prescribing physical activity for women who have experienced stillbirth. Women who have experienced stillbirth have reported that physicians do not counsel about exercise beyond "returning to normal activity" and that they would have liked information about physical activity and/or advice from their physician about being active for their health after their stillbirth [22]. The promotion of positive health behaviors and the positive implications of this is evident in the literature related to women of live births that are active before, during, and after their pregnancies $[32,33]$. It is important to understand the specific and unique needs of women who have experienced stillbirth in order to design interventions to help improve their mental, and physical health outcomes.

Despite a decrease in the number of women who reported participating in regular physical activity during their pregnancy (47\%) compared to before their pregnancy $(60 \%), 61 \%$ of women reported participating in regular physical activity since their stillbirth. This may have been because women who were active knew that exercise might help them feel better [22]. In a study by Huberty and colleagues [22], women who experienced stillbirth and were active prior to their stillbirth reported using physical activity to cope, feel better, and have time alone [22]. This may also be because despite needing to physically recuperate, low to moderate intensity physical activity (i.e., walking, yoga) offers an outlet in which to feel better and have alone time [22]. This is important, as exercise is a wellknown non-pharmacological method to decrease depressive symptoms and reduce episodic recurrences $[16,34]$. However, in our sample less than half of women who reported being active since stillbirth were currently meeting recommendations for physical activity. This is similar to other studies in non-bereaved women during pregnancy and postpartum [35]. It is well known that pregnant women are less active than non-pregnant women and that pregnancy leads to a decrease in physical activity participation [26]. Additionally, physical activity levels postpartum may not return to what they were pre-pregnancy [36,37]. Strategies are needed to help encourage and guide women who experienced stillbirth to use physical activity 
Table 2 Physical activity and depression $(\mathrm{N}=175)$

Participated in PA BEFORE pregnancy $(n=171)$
Participated in DURING pregnancy $(n=171)$
Participated in PA since loss $(n=171)$
Meeting physical activity recommendations $(n=104)$
Ever diagnosed with a depressive mood disorder? $(n=167)$

$$
\begin{aligned}
& \text { n \% } \\
& 102(59.6) \\
& 69(40.4) \\
& 80(46.8) \\
& 91(53.2) \\
& 104(60.8) \\
& 67(39.2) \\
& 38(36.9) \\
& 65(63.1) \\
& 56(33.5) \\
& 111(66.5)
\end{aligned}
$$$$
\text { No }
$$

Mean depression score by time since loss $(n=167)$

$$
\begin{aligned}
& \text { 0-3 months }(n=64) \\
& \text { 4-6 months }(n=33) \\
& \text { 7-12 months }(n=40) \\
& \text { 0-12 months }(n=30)
\end{aligned}
$$

How do you currently cope with depressive symptoms, anxiety, and/ or grief associated with the loss of your baby? $(n=175)$

Engaging/talking with family/friends

Support group

Physical activity (i.e., running, walking, yoga)

Therapist/counselor

Other (please specify)

Anti-depressive medication

Meditation

What type of physical activity specifically do you use to cope? (Check all that apply) \{Responses only included if they answered "physical activity" to the question above $(n=66)$

\section{Brisk walking}

Jogging or running

Other (please specify)

Yoga

Hiking

Biking

Aerobics or aerobic dancing

Swimming

Reasons for participating in physical activity ranked from 1 (most important) to 4 (least important) (Ranks 1 and 2 are combined and reported here) $(n=64)$

Help with depressive symptoms, anxiety, grief

Weight loss

Better overall physical health (i.e., fitness) 


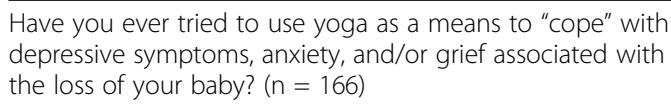

Are you interested in using yoga to cope with depressive symptoms, anxiety, and/or grief associated with the loss of your baby? $(n=137)$

$\begin{array}{ll}\text { Yes } & 66(48.2) \\ \text { No } & 71(51.8)\end{array}$

Rank the settings in which you would prefer to participate in yoga from 1 to 4 . (Ranks 1 and 2 are combined and reported here) $(n=66)$

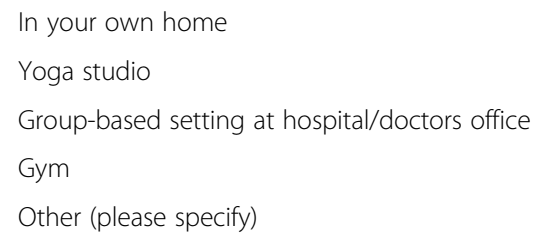

as a means to cope and to help them maintain this activity in the long-term. This is especially important because our study suggests that women who have experienced stillbirth and participate in regular physical activity have less depressive symptoms than women who are not regularly active. Similar findings were reported in women who have postpartum depression after a live birth and participate in exercise programs $[19,38]$. Thus, healthcare providers may consider suggesting exercise after a mother experiences stillbirth as a way to cope with grief and depressive symptoms. Additional research in this area is warranted.

In our study, $38 \%$ of women reported using activity as a means to cope with depressive symptoms, anxiety, and/ or grief associated with the death of their baby. Others reported engaging with family/friends, and support groups to cope with their symptoms. Medical and mental health providers may consider offering group-based exercise programs for women who have experienced stillbirth that incorporate both a social support and exercise component. For example, support groups' session times could be shortened (30 minutes as opposed to 60 minutes) and 30 minutes of yoga or walking could be incorporated. Similar approaches were used in chronic conditions and social support (i.e., group-based) was a known facilitator to improving physical activity participation [39-41]. More research is warranted.

Yoga has burgeoned as an exercise trend in Western society because it positively affects psychological conditions, pain, cardiovascular, autoimmune and immune conditions, and pregnancy outcomes. Based on findings in studies in pregnant and postpartum women and other chronic conditions, yoga represents a potential means of care that may help women build their capacity to be resilient and cope with depressive symptoms both immediately after their stillbirth and in the months and years that follow [41-43]. Even though less than $20 \%$ of women in this study used yoga to cope, 50\% were interested in yoga and of those, most preferred yoga in their home. Studies that examine the feasibility of in-home versus in-studio yoga settings may further inform the design of interventions and help guide low-cost, sustainable strategies for coping after stillbirth.

Our study was the first to describe women's preferences for using physical activity to cope with depressive symptoms after stillbirth. Strategies for interventions to improve the mental and physical health in these women are lacking and the information from this study fills a gap in our knowledge in this area. However, there are some limitations to our study. First, our sample was predominantly Caucasian, educated, and married, therefore the generalizability of our findings to underserved and non-married populations are limited. Second, because the survey was internet-based our sample was limited to those who had access to the Internet and may have been seeking out or already using pregnancy loss support resources. Third, our sample had higher rates of reported physical activity prior to their pregnancy as compared to national levels of physical activity in women of reproductive age [19-21]. This may be because women who were already participating in physical activity or more interested in it may have been more likely to complete the survey. Additionally, physical activity was self-reported and it is well known that self-reported physical activity is often overestimated compared to objectively measured physical activity [44-46]. Given that this study was crosssectional, we cannot infer the direction of effects from our 
linear regression model results. Finally, women who experienced stillbirth more than one year ago were not included in this study and data suggests that these women have levels of depressive symptoms comparable to women within the first year [15]. Information from women post one year from stillbirth in relation to preferences for physical activity could also be very useful to inform future interventions.

\section{Conclusion}

Women who have experienced stillbirth experience negative mental and physical health outcomes as a result of their stillbirth, many of which may impact subsequent pregnancies. Current inter-conception interventions are non-existent or based upon women who have experienced live births. Women who have experienced stillbirth may be interested in physical activity interventions to help them cope, feel better, and have alone time. Additionally, women may be interested in improving their mental (i.e., depressive symptoms) and physical (i.e., weight) health for subsequent pregnancies. Women report using activity to cope and are most interested in walking, jogging, or yoga interventions, all of which are low cost, non-pharmacological solutions to help improve depressive symptoms. Physical activity interventions may provide opportunities for health care professionals to help women cope with depressive symptoms after their stillbirth. More research in this area is warranted.

\section{Competing interests}

The authors declare that they have no competing interests.

\section{Authors' contributions}

All authors' contributed equally to this work. JH conceived the study, designed and implemented the survey, and prepared the manuscript; JAN contributed to the design and implementation of the survey, and the preparation of the manuscript; KJG contributed to the design and implementation of the survey, and the preparation of the manuscript; $L R$ contributed to the design and implementation of the survey, collected and analyzed data, and contributed to the preparation of the manuscript; JC contributed to the design and implementation of the survey, and the preparation of the manuscript; DBM contributed to the design of the survey, designed the data analysis, analyzed data, and contributed to the preparation of the manuscript. All authors read and approved the final manuscript.

\section{Acknowledgement}

The authors would like to acknowledge all of the bereaved mothers who were willing to participate in this research study and share information about their experience after stillbirth.

\section{Author details}

${ }^{1}$ Exercise and Wellness, Arizona State University, Phoenix, AZ, USA.

${ }^{2}$ Community and Behavioral Health, Colorado School of Public Health, Aurora, CO, USA. ${ }^{3}$ Department of Family Medicine, University of Michigan, Ann Arbor, MI, USA. ${ }^{4}$ Department of Obstetrics \& Gynecology, University of Michigan, Ann Arbor, MI, USA. ${ }^{5}$ School of Social Work, Arizona State University, Phoenix, AZ, USA. ${ }^{6}$ College of Nursing and Health Innovation, Arizona State University, Phoenix, AZ, USA.

Received: 18 July 2014 Accepted: 6 November 2014

Published online: 29 November 2014

\section{References}

1. Centers for Disease Control and Prevention (CDC), National Centers for Health Statistics, U.S. Department of Health and Human Services: Perinatal Mortality in the United States: Preliminary Data for 2003. Washington, DC 2003.

2. Kowaleski J: State Definitions and Reporting Requirements. Hyattsville: National Center for Health Statistics; 1997.

3. Cacciatore J, Frøen JF, Killian M: Condemning self, condemning other: blame and mental health in women suffering stillbirth. J Ment Health Counsel 2013, 35:342-359.

4. Cacciatore J: Stillbirth: a patient-centered psychosocial care. Clin Obstet Gynecol 2010, 53:691-699.

5. Grekin $\mathrm{R}, \mathrm{O}^{\prime}$ Hara MW: Prevalence and risk factors of postpartum posttraumatic stress disorder: a meta-analysis. Clin Psychol Rev 2014, 34:389-401.

6. Hughes PM, Turton P, Evans CDH: Stillbirth as a risk factor for depression and anxiety in the subsequent pregnancy: a cohort study. BMJ 1999, 14:1721-1724.

7. Blackmore ER, Côté-Arsenault D, Tang W, Glover V, Evans J, Golding J, O'Connor TG: Previous prenatal as a predictor of perinatal depression and anxiety. Br J Psychiatry 2011, 14:373-378.

8. Gold KJ, Johnson TR: Mothers at risk: maternal mental health outcomes after perinatal death. Obstet Gynecol 2014, 123(Suppl 1):6S

9. Frøen F, Cacciatore J, McClure EM, Kuti O, Jokhio AH, Islam M, Shiffman J: Still births: why they matter. Lancet 2011, 377:1353-1366.

10. Côté-Arsenault D, Marshall R: One foot in-one foot out: weathering the storm of pregnancy after perinatal loss. Res Nurs Health 2000, 23:473-485.

11. Gaudet C: Pregnancy after perinatal loss: association of grief, anxiety and attachment. J Reprod Infant Psychol 2010, 28:240-251.

12. DeBackere KJ, Hill PD, Kavanaugh KL: The parental experience of pregnancy after perinatal loss. JOGNN 2008, 37:525-537.

13. Kotelchuck M: Improving the Health of Women following Pregnancy: Inter-Conception Care. [http://www.hrsa.gov/advisorycommittees/mchbadvisory/ InfantMortality/Meetings/20130424/kotelchuck.pdf]

14. Lacasse JR, Cacciatore J: Prescribing of psychiatric medication to bereaved parents following perinatal/neonatal death: an observational study. Death Stud 2014, 0:1-8.

15. Cacciatore J: Psychological effects of stillbirth. Fetal Neonatal Med 2013, 18(2):76-82.

16. Babyak M, Blumenthal J, Herman S, Khatri P, Doraiswamy M, Moore K, Edward CW, Baldewicz T, Krishnan K: Exercise treatment for major depression: maintenance of therapeutic benefit at 10 months. Psychosom Med 2000, 62:633-638.

17. Herring MP, Puetz TW, O'Connor PJ, Dishman RK: Effect of exercise training on depressive symptoms among patients with a chronic illness: a systematic review and meta-analysis of randomized controlled trials. Arch Intern Med 2012, 72:101-111.

18. Dunn AL, Trivedi MH, Kampert JB, Clark CG, Chambliss HO: Exercise treatment for depression: efficacy and dose response. Am J Prev Med 2005, 28:1-8.

19. Teychenne M, York R: Physical activity, sedentary behavior, and postnatal depressive symptoms: a review. Am J Prev Med 2013, 45:217-227.

20. Evenson KR: Towards an understanding of change in physical activity from pregnancy through postpartum. Psych Sport Exerc 2011, $12: 36-45$.

21. Lewis B, Avery M, Jennings E, Sherwood N, Martinson B, Crain AL: The effect of exercise during pregnancy on maternal outcomes: practical implications for practice. Am J Lifestyle Med 2008, 2:441-455.

22. Huberty JL, Coleman J, Rolfsmeyer K, Wu S: A qualitative study exploring women's beliefs about physical activity after stillbirth. BMC Pregnancy Childbirth 2014, 14:1471-2393.

23. Craft LL, Perna FM: The benefits of exercise for the clinically depressed. Prim Care Companion J Clin Psychictry 2004, 6:104-111.

24. Da Costa D, Ireland K: Perceived benefits and barriers to leisure-time physical activity during pregnancy in previously inactive and active women. Women Health 2013, 53:185-202.

25. Santos PC, Abreu S, Moreira C, Lopes D, Santos R, Alves O, Silva P, Montenegro N, Mota J: Impact of compliance with different guidelines on physical activity during pregnancy and perceived barriers to leisure physical activity. J Sports Sci 2014, 32(14):1398-1409.

26. Evenson KR, Moos MK, Carrier K, Siega-Riz AM: Perceived barriers to physical activity among pregnant women. Matern Child Health J 2009, 13:364-375. 
27. Leiferman J, Swibas T, Koiness K, Marshall JA, Dunn AL: My baby, my move: examination of perceived barriers and motivating factors related to antenatal physical activity. J Midwifery Womens Health 2011, 56:33-40.

28. Marcus B, Forsyth L: Motivating People to Be Physically Active $2^{\text {nd }}$ ed. Chapain: Human Kinetics; 2009.

29. Turton P, Hughes P, Evans CDH, Fainman D: Incidence, correlates and predictors of post-traumatic stress disorder in the pregnancy after stillbirth. BJ Psych 2001, 178:556-560.

30. Derogatis LR, Lipman RS, Rickels K, Uhlenhuth EH, Covi L: The Hopkins symptom checklist (hscl): a self-report symptom inventory. Behav Sci 1974, 19:1-15.

31. Centers for Disease Control and Prevention: [http://www.cdc.gov/physicalactivity/ everyone/guidelines/index.html]

32. Pearce EE, Evenson KR, Downs DS, Steckler A: Strategies to promote physical activity during pregnancy: a systematic review of intervention evidence. Am J Lifestyle Med 2013, 7:1-19.

33. Downs DS, Chasan-Taber L, Evenson KR, Leiferman J, Yeo S: Physical activity and pregnancy: past and present evidence and future recommendations. Res Q Exerc Sport 2012, 83:485-502.

34. Demissie Z, Siega-Riz AM, Evenson KR, Herring AH, Dole N, Gaynes BN: Physical activity during pregnancy and postpartum depressive symptoms. Midwifery 2013, 29:139-147.

35. Doran FM, Buckley NA: Walking patterns in pregnancy. Aust J Prim Health 2013, 19:213-218

36. Evenson KR, Herring AH, Wen F: Self-reported and objectively measured physical activity among a cohort of postpartum women: the pin postpartum study. J Phys Act Health 2012, 9:5-20.

37. Gaston A, Cramp A: Exercise during pregnancy: a review of patterns and determinants. J Sci Med Sport 2011, 14:299-305.

38. Ko YL, Yang $C L$, Fang $C L$, Lee MY, Lin PC: Community-based postpartum exercise program. J Clin Nurs 2013, 22:2122-2131.

39. Naumann F, Munro A, Martin E, Magrani P, Buchan J, Smith C, Piggott B, Philpott M: An individual-based versus group-based exercise and counselling intervention for improving quality of life in breast cancer survivors. A feasibility and efficacy study. Psychooncology 2012, 21:1136-1139.

40. Tulloch H, Sweet SN, Fortier M, Capstick G, Kenny GP, Sigal RJ: Exercise facilitators and barriers from adoption to maintenance in the diabetes aerobic and resistance exercise trial. Can J Diabetes 2013, 37:367-374.

41. Yadav RK, Magan D, Mehta M, Mehta N, Mahapatra SC: A short-term, comprehensive, yoga-based lifestyle intervention is efficacious in reducing anxiety, improving subjective well-being and personality. Int J Yoga 2012, 5:134-139.

42. Da Costa D, Lowensteyn I, Abrahamowicz M, lonescu-Ittu R, Dritsa M, Rippen N, Cervantes P, Khalifé S: A randomized clinical trial of exercise to alleviate postpartum depressed mood. J Psychosomatic Obstet Gynecol 2009, 30:191-200.

43. Smith C, Hancock H, Blake-Mortimer J, Eckert K: A randomised comparative trial of yoga and relaxation to reduce stress and anxiety. Complement Ther Med 2007, 15:77-83.

44. Tucker JM, Welk GJ, Beyler NK: Physical activity in U.S. adults compliance with the physical activity guidelines for americans. Am J Preventative Med 2011, 40:454-461.

45. Prince SA, Adamo KB, Hamel ME, Hardt J, Gorber SC, Tremblay M: A comparison of direct versus self-report measures for assessing physical activity in adults: a systematic review. Int J Behav Nutr Phys Act 2008, 5:1-24.

46. Schuna JM, Johnson WD, Tudor-Locke C: Adult self-reported and objectively monitored physical activity and sedentary behavior. Int J Behav Nutr Phys Act 2013, 10:1-12.

doi:10.1186/s12884-014-0391-1

Cite this article as: Huberty et al:: Physical activity and depressive symptoms after stillbirth: informing future interventions. BMC Pregnancy and Childbirth 2014 14:391.

\section{Submit your next manuscript to BioMed Central and take full advantage of:}

- Convenient online submission

- Thorough peer review

- No space constraints or color figure charges

- Immediate publication on acceptance

- Inclusion in PubMed, CAS, Scopus and Google Scholar

- Research which is freely available for redistribution

Submit your manuscript at www.biomedcentral.com/submit
Ciomed Central 